\title{
A percepção e interpretação ambiental do rio das Antas de Taubaté, SP
}

The Perception and Environmental Interpretation of Antas River in Taubaté, SP

$$
\begin{aligned}
& \text { *Lucia Helena Ramos Martins }{ }^{1} \\
& \text { Cyro de Barros Rezende Filho }{ }^{2}
\end{aligned}
$$

${ }^{1}$ Secretaria da Educação do Estado de São Paulo - E.E. Monteiro Lobato

Rua Professor Clóvis Winther, 625, Jardim Maria Augusta, 12080-480, Taubaté, SP, Brasil

\author{
luherama@gmail.com \\ ${ }^{2}$ Universidade de Taubaté - UNITAU
}

Estrada Mun. Dr. José Luiz Cembranelli, 5.000- 12080-010 - Taubaté - SP, Brasil

profcyro@yahoo.com.br

\begin{abstract}
The present work has the objective to develop the spirit of feeling and environmental perception and also to provide the scientific acquisition of knowledge and abilities to the basic education students of the E. E. Monteiro Lobato, in Taubaté city, State of São Paulo, having as aim of research, a survey, analyses and reflection about micro basin of Antas river. The used methods to this survey have been: 1) Survey of the previous knowledge of the students about the environmental problems in question, with development of a critical vision facing of the recognition of the real local; 2) analysis of the aspects of the environment, as well as its characteristics, and the diagnostic through the visits "in locus", with information files and activities of rediscover, and the previous knowledge. 3) Debate and construction of the micro it has a objective to improve previously topics worked and expose experiences in the scientific social field, in which the students make up the knowledge.
\end{abstract}

Key word: ambient perception; micro basin; water; mockup; sensitivity. 


\section{Introdução}

A Educação Ambiental é um processo de formação e informação orientado para o desenvolvimento da consciência crítica sobre as questões ambientais. No Brasil, a Educação Ambiental teve seu primeiro espaço legal na Constituição Federal de 1988 (Brasil, 1997), cuja regulamentação ocorreu por meio da Lei Federal n.9795, sancionada em 27 de abril de 1999, criando-se, assim, a Política Nacional de Educação Ambiental - PNEA. O emprego desse tema na educação, finalmente, deu-se por meio dos Parâmetros Curriculares Nacionais (Brasil, 1998), nos quais refletem as decisões e tratados das grandes conferências e legislação ambiental. A Educação Ambiental é abordada, nos PCNs, como um tema transversal de caráter interdisciplinar.

Como professora de História, no ensino fundamental, preocupada com a aquisição da consciência ambiental dos alunos, venho desenvolvendo há oito anos vários projetos, tais como: visitas ao aterro sanitário do município, atividades de trilhas interpretativas e, mais recentemente, estudo da microbacia das Antas. Nesse último, as pesquisas estão sendo desenvolvidas há mais de 2 anos com alunos de $8^{a}$ série da Escola Estadual Monteiro Lobato. Esse é o projeto que se faz alvo da presente discussão.

O local de estudo foi delimitado à unidade do Viveiro Florestal de Taubaté, órgão pertencente ao Instituto Florestal. A Unidade de Conservação Viveiro Florestal foi criado pelo Decreto $\mathrm{n}^{\circ} 36.771$ de 15 de maio de 1960, com a finalidade de produzir eucalipto e pinus e substituir o corte de árvores nativas. Atualmente o viveiro reproduz espécies nativas para reflorestamento e mantêm por meio do Projeto Vale Vida, visitas monitorados com auxílio da polícia florestal. Que é direcionado aos estudantes do ensino fundamental, e transmite conhecimentos sobre o meio ambiente. Por meio de visita ao museu de animais taxidermizados, coleção entomológica, trilha interpretativa e breve orientação de como formar um viveiro. Durante a atividade de trilha interpretativa é possível atentar para a riqueza da flora e identificar espécies nativas e exóticas presentes na mata capoeira. Também, apreciar a água brotando da nascente do rio das Antas; bem como observar em suas margens o reflexo das ações antrópicas sob a forma de sedimentação, erosão e assoreamento. Espera-se que, ao participar de atividades práticas em contato com o meio ambiente, o aluno possa refletir e repensar a prática cotidiana. Busca-se, por meio de economia de água, energia e prática de seleção do lixo, forma imediata de redução do consumo de recursos naturais. Portanto o presente trabalho tem como objetivo geral contribuir para a formação da cidadania ambiental. E como objetivo específico desenvolver a Educação Ambiental por meio da produção de desenhos, mapas e, principalmente, maquetes da microbacia das Antas. Esperase que os alunos, ao conhecerem, identificarem e avaliarem as alterações antrópicas causadas pela atuação humana, desenvolvam a percepção e possam optar pelo exercício de conduta responsável a respeito do meio ambiente que lhes garanta a qualidade de vida na atualidade e no futuro. A construção de materiais concretos com destaque para as maquetes, tem a finalidade de conceituar temas previamente trabalhados, além de proporcionar uma experiência significativa no campo sociocientífico em que os alunos tenham oportunidade de demonstrar sua capacidade de realizar, difundir e intercambiar informações e conhecimentos científicos, fortalecendo o vínculo entre a escola e a comunidade. 


\section{Objetivos}

O presente trabalho tem como objetivo desenvolver o espírito de sensibilidade e percepção ambiental e proporcionar aos alunos do ensino fundamental a aquisição de conhecimentos e habilidades para resolver problemas ambientais existentes na sua própria comunidade. E despertar o interesse pela melhoria da qualidade de vida por meio de novas atitudes presentes no cotidiano.

\section{Metodologia}

O presente trabalho foi desenvolvido na E.E. Monteiro Lobato, o primeiro estabelecimento a instalar o ensino médio na cidade de Taubaté, em 1932. Foi realizado durante o ano de 2007, de março a dezembro. O trabalho foi exposto na feira cultural e científica da escola e no Seminário de Educação Ambiental do Vale do Paraíba. O grupo de estudo foi composto por 20 alunos da $8^{\text {a }}$ série do Ensino fundamental da E. E. Monteiro Lobato. Com idade entre 14 e 15 anos, provenientes de diversos bairros da cidade. O restante, 10 alunos, atuou em diversas tarefas em colaboração com os colegas. Porém, faltou-lhes comprometimento necessário para que todas as etapas fossem executadas e, em posse dos diagnósticos analisados, não permitiu ao professor definir as estratégias para o cumprimento dos objetivos.

Segundo Matuí (1995), nessa faixa etária, o indivíduo compreende as operações formais ou abstratas e tem oportunidade de construir os mediadores finais que lhes permitirão conceituar o mundo e as coisas relativas ao nível científico e filosófico. Atentou-se para os aspectos de envolvimento dos sujeitos participantes, para a otimização do tempo e do espaço, bem como para a abordagem dos conteúdos conceituais, procedimentais e atitudinais como possibilidade de encaminhamento metodológico para o grupo. Também pensou-se em atividades que permitissem explorar os conhecimentos individuais, por meio de apresentação oral, formulando idéias e proposituras. A metodologia utilizada foi interacionista/construtivista, baseada na teoria construtivista sócio-histórica, com grande influência de Piaget, quanto ao aspecto cognitivo (Piaget,1986).

De Vygotski (2003), quanto aos aspectos sócio-históricos. E Wallon, quanto aos aspectos afetivos de personalidade. (apud Matuí, 1995). Esses autores concordam que o desenvolvimento e a aprendizagem não são resultantes só dos estímulos externos (objeto), nem só da produção da razão (sujeito), mas fruto da interação dos dois: sujeito e objeto (Matuí, 1995). Utilizou-se o método da prática social de Saviani (1991), construtivismo, sócio-histórico, porque acrescenta a teoria ao método inserindo o modelo de passagem da ação para a conceituação.

As experiências metodológicas utilizadas no presente trabalho, tais como: a confecção de desenhos, mapas e maquetes, referem-se à educação como prática social, embasada nas práticas sugeridas por Piaget (1986), Vigotski (2003), Saviani (1991), Vianna et al. (1994), Cpzasky (Brasil, 2008), Matuí (1995) e Sato e Carvalho (2006). Utilizou-se técnica de aprendizagem que tem como instrumento pedagógico a produção do material concreto; com a finalidade de desenvolver a percepção, a sensibilidade, além da inserção de práticas investigativas. E teve todos os seus momentos registrados, os quais serão apresentados a seguir. 


\section{Resultados e discussões}

O estudo da bacia hidrográfica como unidade experimental, possibilitou aos envolvidos uma visão integrante e sistêmica dos elementos naturais dos quais fazem parte. Por meio de conhecimentos prévios levantados e discutidos em sala de aula e no campo, os alunos puderam entender o local de estudo. Analisou-se e refletiu-se sobre as ações preventivas e possíveis soluções para os problemas levantados, identificando os aspectos geográficos, característicos de uma bacia hidrográfica e, discutiu-se a importância da manutenção do ciclo da água e da vegetação para que se mantenha a continuidade do abastecimento de água, que permita à região maior umidade do ar, principalmente, nas estações secas e que são necessárias à qualidade de vida. Os educando foram avaliados por meio do envolvimento e da participação nas atividades propostas. Qualitativamente, por meio da observação da capacidade de memorizar os conhecimentos e mudar as atitudes de comportamentos. Pela incorporação de valores e do estabelecimento das competências: da capacidade de tomar decisões e de participar de discussões consensuais e da disseminação de conceitos.

Foi possível avaliar a proposta metodológica aplicada no presente trabalho e observar as habilidades e competências desenvolvidas pelos alunos durante todo o processo e durante a apresentação do material obtido: desenhos, textos (prática de redescoberta), confecção de maquetes e participação efetiva nas discussões, atividades do meio, registro por meio de prática de redescoberta, trilha interpretativa e apresentação final do trabalho.

Os desenhos produzidos representaram conhecimentos adquiridos pelas atividades educativas e proporcionados pela aquisição de conhecimentos prévios, palestras, exibição de filmes, documentários e vivência própria. O primeiro desenho representa a visão que os habitantes de Taubaté têm em relação ao rio Paraíba do Sul, distante $6 \mathrm{~km}$ da cidade, sempre observado através de uma ponte.

O desenho mostra aspectos que são próprios dos rios da cidade de Taubaté: pouca mata ciliar e solo exposto. $\mathrm{O}$ aluno representou o rio de cor azul, porém, em geral, nossos rios apresentam cor escura devido à presença de sedimentos (figuras 1 e 2).

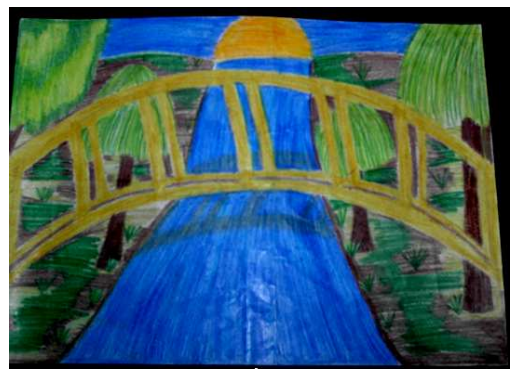

figura 1 - Desenho: rio de Taubaté

Crédito: Lucia Helena

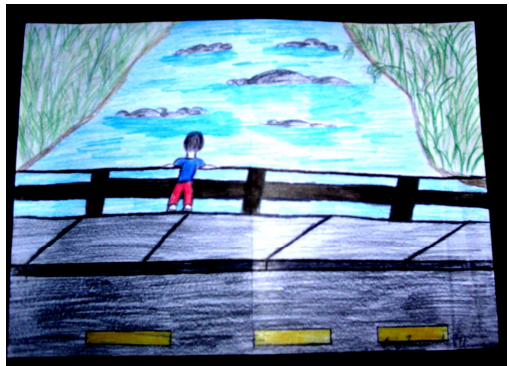

figura 2 - observação do rio

Crédito: Lucia Helena 
A figura 2 representa o diagnóstico que observamos in loco e a imagem de satélite: o assoreamento do rio devido à ausência de mata ciliar e a erosão. Lá, as margens são representadas por capim ralo em toda a bacia do Una, o pasto é plantado até a borda do rio e o gado vaga livremente. Os bancos de areia e a sedimentação são realidades muito próximas e vivenciadas pelo aluno. A cor azul reflete a esperança de manutenção das bacias hidrográficas para garantir a qualidade de vida da população que necessita desse recurso natural para sua existência.

A produção de maquetes foi um recurso utilizado para despertar o interesse do aluno, aprofundar conceitos estudados em sala de aula e posteriormente vivenciados em atividades, in loco, de trilha interpretativa e registro em atividade de redescoberta (Sponton, 2005; Tagein, 2005; Hennig, 1996). Possibilitou-se a contextualização dos dados e a compreensão do diagnóstico socioambiental. Segundo Almeida (2006) a construção de maquetes favorece a representação e possibilita o domínio visual do espaço a partir do modelo. Permite ao aluno ver o todo e, portanto, refletir sobre ele.

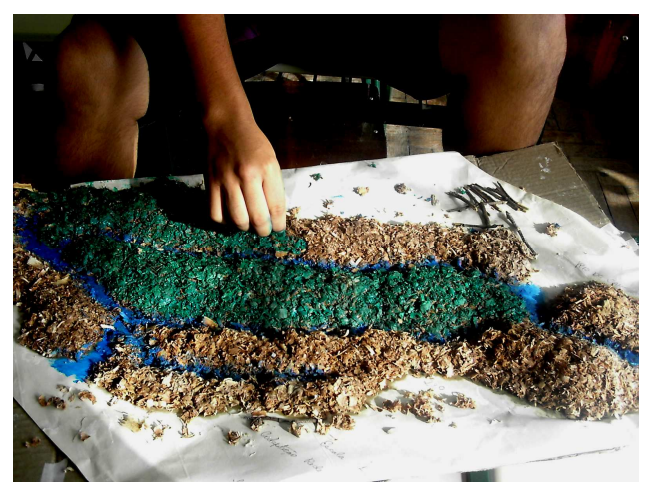

figura 3 - Maquete do rio Paraíba do Sul - Crédito: Lucia Helena

A produção da maquete dessa bacia teve o objetivo de demonstrar: o curso do rio Paraíba e sua formação, o padrão de drenagem (exorréico), ou seja, deságua no Oceano Atlântico devido às elevadas altitudes na porção Ocidental da América do Sul (a cordilheira dos Andes), os rios brasileiros vão todos desaguar no Oceano Atlântico. Mesmo aqueles que correm para o oeste, acabam fazendo uma curva ou então deságuam em outro rio que, inevitavelmente, irá para o Atlântico. Na maquete, é possível comprovar essa teoria, pois o rio Paraíba retorna em um cotovelo na cidade de Guararema para o litoral do Rio de Janeiro (figura 3)

A produção da maquete (uso e ocupação do solo) da microbacia das Antas teve como objetivo compartilhar as experiências de aprendizagem. Discutir o ciclo e os múltiplos usos da água, o desmatamento e a ausência de mata ciliar. Confrontando os conhecimentos adquiridos com outras bacias e socializando com alunos de outras turmas da escola, pais e professores durante a feira escolar e o simpósio de Educação Ambiental. (figura 4 e 5 ). 


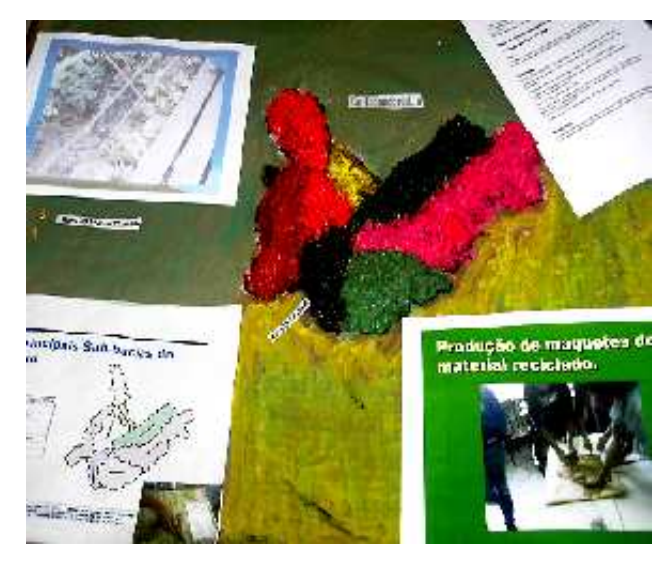

figura 4 - Representação da bacia do Una, localização da microbacia das Antas. Fonte Repositório do Una. Crédito: Lucia Helena

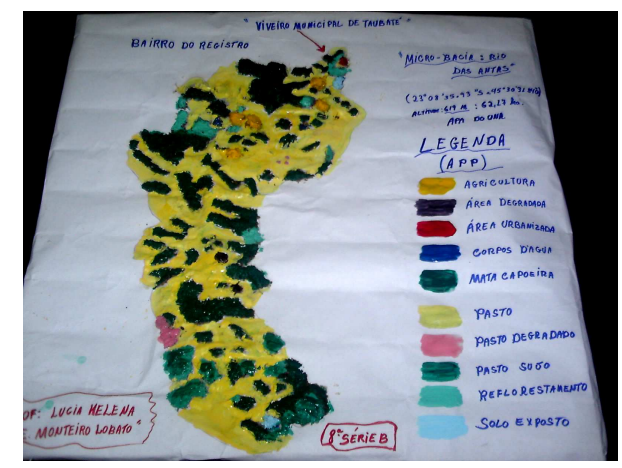

Figura 5 - Representação do mapa de uso e de ocupação do solo da microbacia das Antas, com identificação do Viveiro Florestal. Fonte LAGEO.

\section{Crédito: Lucia Helena}

Ao reconstruir a bacia hidrográfica a partir da produção de maquete, o objetivo é contextualizar e gerar práxis, (ação-reflexão-ação). Gerar a ressignificação entre o objeto e o meio como um elo entre o homem urbano e a natureza. Ressaltando a sua relação de dependência e levando o aluno a vivenciar e assumir uma postura crítica que inclua, em seu dia-a-dia, as práticas para minimizar os problemas ambientais.

\section{Conclusões}

A conclusão dos alunos foi à seguinte: a microbacia do rio das Antas tem representado no mapa de uso e ocupação do solo, na cor amarela, o pasto que ocupa até as margens do rio. A mata ciliar está presente somente no Viveiro Municipal e em alguns pontos isolados. Portanto, o resultado da ação antrópica na microbacia das Antas é perceptível sob a forma de enxurrada, erosão, assoreamento e sedimentação observados no curso do rio. 


\section{Referências Bibliográficas}

Abramowicz, M. (2006) Uma prática docente iluminada pelas reflexões de Paulo Freire. Em: Saul, A. M. (org.). Paulo Freire: um pensamento atual para compreender e pesquisar questões do nosso tempo: ètica, docência e políticas públicas de educação. p. 139-146. São Paulo ; Editora Articulação Universidade/Escola.

Abreu, M. M. B. (1991) Taubaté: de núcleo irradiador de bandeirismo a centro industrial e universitário do Vale do Paraíba. $2^{\mathrm{a}}$ ed. Aparecida-SP: Santuário.

Almeida, R. D. de. (2006) Do desenho ao mapa: iniciação cartográfica na escola. $4^{\mathrm{a}}$ ed. São Paulo: Contexto.

Brasil. (1997) Constituição da república federativa do Brasil: promulgada em 5 de outubro de 1988. - 16 a edição - atual. e ampl. São Paulo: Saraiva. (Coleção Saraiva de Legislação).

Brasil. (1998) Secretaria de Educação Fundamental. Parâmetros curriculares nacionais: terceiro e quarto ciclos: apresentação dos temas transversais. Brasília: MEC/SEF. 436p.

Brasil. (2008) Água./ texto de Silvia Czapski. Brasília: Ministério da Educação: Secretaria de Educação Continuada, Alfabetização e Diversidade - SECAD; Ministério do Meio Ambiente, Secretaria de Articulação Institucional e Cidadania Ambiental - SAIC. 20p. (Mudanças ambientais globais: pensar + agir na escola e na comunidade).

Henning, G. J. (1986) Metodologia do ensino de ciências. Porto Alegre: Mercado Aberto, Porto Alegre-RS. 416p. (Série Novas Perspectivas, 18)

Matuí, J. (1995) Construtivismo: teoria construtivista sócio histórica aplicada ao ensino - São Paulo: Moderna.

Oliveira, E. S.; Dias, N. W. ; Batista, G. T. (2006) Análise físicoambiental da bacia do rio Una: suporte à análise físico-química da água. Em: ENCONTRO ÁGUA E FLORESTA, 2006, Taubaté. Anais... Encontro Água e Floresta.

PIAGET, J. (1986) A linguagem e o pensamento da criança. 4.ed. São Paulo: Martins Fontes.

Rivelli, E. A. L. (2005) Evolução da legislação ambiental no Brasil: políticas de meio ambiente, educação ambiental e desenvolvimento urbano, Cap. 11. Em: Philippi Jr, A.; Pelicioni, M. C. (Ed.) Educação ambiental e sustentabilidade. p. 285-302. Barueri: Manole. (Coleção Ambiental, 3).

Sato, M.; Carvalho, I. (orgs.) (2006) Educação ambiental: pesquisa e desafios. Porto Alegre: Artmed.

Saviani, D. (1991) Pedagogia histórico-crítica: primeiras aproximações. São Paulo: Cortez Autores Associados. (Coleção Polêmicas do nosso tempo).

Silva, S. S.; Batista, G. T.; Targa, M. dos S.; Dias, N. W. (2007) Análise de impactos ambientais gerados pela construção de uma barragem na Bacia do Médio Una, Taubaté, SP. Em: SEMINÁRIO DE RECURSOS HÍDRICOS DA BACIA HIDROGRÁFICA DO 
PARAÍBA DO SUL: O EUCALIPTO E O CICLO HIDROLÓGICO, 1., 2007. pp. 43-50. São Paulo. Anais... Taubaté-SP: IPABHI, UNITAU.

Sponton, M. H. da C. (2005) Arte: espaço de investigação, construção e humanização. Cap. 20. Em: Philippi Jr, A.; Pelicioni, M. C. (Ed.) Educação ambiental e sustentabilidade. p.479502. Barueri: Manole. (Coleção Ambiental, 3).

Tagein, E. A. (2005) Ambientar: arte na educação, Cap. 19. Em: Philippi Jr, A.; Pelicioni, M. C. (Ed.) Educação ambiental e sustentabilidade. p. 467-468. Barueri: Manole. (Coleção Ambiental, 3).

Tundisi, J. G. (2005) Água no século XXI: enfrentando a escassez. $2^{\mathrm{a}}$ ed. São Carlos: RiMa, IIE, 248p.

Vianna, A. (org.); Ribeiro, V. M.; Menezes, L.; Iorio, M; C. (1994) Educação ambiental: uma abordagem pedagógica dos temas da atualidade. $2^{\mathrm{a}} \mathrm{ed}$. rev. Ampl. Rio de Janeiro: CEDI: Koinonia; São Paulo: Ação Educativa; Erexim-RS: CRAB, 88p. (Programa Nacional do Professor - MEC - FAE).

Vygotiski, L. S. (2003). Psicologia pedagógica. Porto Alegre: Artmed.

Notas:

(1) Maragon, C. (2003)Um terrário para observar o ciclo da água. Rev. Nova Escola, n.165, p.40-41, set, 2003. Disponível em:

http://revistaescola.abril.com.br/edicoes/pdf/Esp_005/terrario.pdf, acessado em abril/2007.

(2) Cícero, C. M.; Catelani, C. de S.; Batista, G. T. (2006) Reposição florestal e educação ambiental na Bacia do Rio Una, Bacia do Paraíba do Sul. Em: SEMINÁRIO G\&DR/MCA ATIVIDADES RURAIS NO VALE DO PARAÍBA - DO CICLO DO CAFÉ AOS NOSSOS DIAS, 14., 2006. Mesa redonda... Taubaté: Unitau, 2006. 40p. Disponível em: http://www.agro.unitau.br:8080/dspace/handle/2315/70 (Una_Reposicao_Red.pdf)

(3) Batista, G. T.; Targa, M. dos S.; Catelani, C. de S. (2006) Plano de bacias do rio Una: resultado do Projeto Una. Em: SEMINÁRIO G\&DR/MCA - ATIVIDADES RURAIS NO VALE DO PARAÍBA - DO CICLO DO CAFÉ AOS NOSSOS DIAS, 14., 2006. Mesa redonda... Taubaté: Unitau, 2006. Disponível em: http://www.agro.unitau.br:8080/dspace/handle/2315/69 (Una_Ativ_Rural2_Red_Red.pdf), acessado em abril de 2007. 